\title{
Iodine Deficiency in Pregnant Women Pre- and Post-Mandatory Iodine Fortification in Australia - An Epidemiological Review
}

\author{
Kamil J Wegrecki ${ }^{1}$, Richard R Sadig ${ }^{1 *}$, Jason Aramideh, Nusrath Khan, Daniel Moawad, Joe Jabbour \\ and Andria May Yaourtis ${ }^{2}$ \\ 1) Faculty of Medicine, University of Notre Dame Sydney, 160 Oxford St, Darlinghurst NSW 2010, Australia \\ 2) School of Chemistry, University of Sydney, the University of Sydney, F11, Eastern Ave, Sydney NSW 2006
}

*Corresponding author: Sadig RR, Faculty of Medicine, University of Notre Dame Sydney, 160 Oxford St, Darlinghurst NSW 2010, Australia, Tel: +61 2 95945671; Fax: +61 2 95333712; E-mail: richard.sadig1@my.nd.edu.au

Received date: 04 September 2017; Accepted date: 19 September 2017; Published date: 26 September 2017

Copyright: (c) 2017 Wegrecki KJ, et al. This is an open-access article distributed under the terms of the Creative Commons Attribution License, which permits unrestricted use, distribution, and reproduction in any medium, provided the original author and source are credited.

\begin{abstract}
Adequate iodine nutrition is necessary during pregnancy and breastfeeding for proper neurodevelopment in offspring. lodine deficiency is common in developed nations and persists despite various public health interventions. This review examines the effect of mandatory iodine fortification of food on iodine status in pregnant women in Australia. Although iodine status has improved, additional supplementation is still required to achieve adequate iodine levels in pregnant and breastfeeding women.
\end{abstract}

Keywords: Iodine fortification; Nutrition supplementation; Thyroid hormone; Pregnant women

\section{Background}

Iodine deficiency is common in Australia where dietary intake appears to have declined over the course of the decade before mandatory iodine fortification was introduced in 2009 [1-3]. Surprisingly, the aforementioned trend prior to 2009 had emerged despite various other programs to reduce the burden and resulted in Australia being classified as a mild-to-moderately iodine- deficient country by the World Health Organization (WHO) [4].

As a precursor to thyroid hormone, iodine has a central role in normal thyroid function. Thyroid hormones play a key role in regulating metabolism and influence fetal and childhood physical and cognitive development [5]. Therefore, adequate iodine nutrition is particularly important for pregnant women and young children. During pregnancy, the demand for iodine increases in proportion to the needs of the foetus and increased maternal iodide clearance by the kidneys [6]. As such, pregnant women are vulnerable to developing iodine deficiency, which can cause neurodevelopmental changes in offspring [7,8]. Indeed, reduced academic outcomes have been documented in children born to iodine-deficient mothers $[9,10]$. Studies have demonstrated that up to $20-40 \%$ of mothers tested in Melbourne were moderately to severely iodine-deficient [11].

The Australia and New Zealand Food Regulation Ministerial Council made the Food Standards Australia New Zealand (FSANZ) implement food fortification to reduce neural tube defects and address the re-emergence of iodine deficiency in Australia and New Zealand [12]. This culminated in the revision of the Australia New Zealand Food Standards Code in 2009, which marked the beginning of mandatory iodine and folate fortification of food. Standard 2.1.1 of the Code requires the addition of folic acid to wheat flour in Australia and the use of iodized salt in bread-making in both Australia and New Zealand. The Standard excludes bread marked as 'organic' from complying with these requirements in both countries [13].
Median urinary iodine concentration (MUIC) is an indirect measure of iodine status and is determined from spot urine samples. Except in breastfeeding women, urinary iodine excretion accurately reflects recent iodine intake, with about $90 \%$ of dietary iodine appearing in the urine [14]. Although not a sufficient measure for individual iodine status, MUIC can be used to validly assess the population status [15].

The World Health Organization (WHO) considers a population mildly iodine deficient if the MUIC is less than $100 \mu \mathrm{g} / \mathrm{L}$, and moderately iodine deficient if the MUIC is less than $50 \mu \mathrm{g} / \mathrm{L}$. The WHO recommends that no more than $20 \%$ of the population be moderately iodine deficient [16]. Since requirements in pregnancy are increased, the NHMRC recommends that all women who are pregnant, breastfeeding or considering pregnancy, take an iodine supplement of $150 \mu \mathrm{g} / \mathrm{L}$ each day [17].

Given the extent of deficiency and the fact that it may be largely asymptomatic to confer a negative impact on neonatal outcome, a community-centered approach is vital in reducing future neurodevelopmental issues. Moreover, if population-based strategies fail to adequately address the problem in all groups in the past, the identification of those at highest risk may alert primary care physicians and obstetricians to suspect iodine deficiency in these patients with early recourse to treatment.

\section{Aims and Objectives}

This report is a review of the literature with regard to those groups of women that are at highest risk of iodine deficiency before and after mandatory iodine fortification in Australia.

The key question the report will seek to answer is: How effective have fortification of foods and prenatal iodine supplementation been in reducing iodine deficiency in pregnant women? 
Citation: Wegrecki KJ, Sadig RR, Aramideh J, Khan N, Moawad D, Jabbour J, Yaourtis AM, et al. (2017) lodine Deficiency in Pregnant Women Pre- and Post-Mandatory lodine Fortification in Australia - An Epidemiological Review. Vitam Miner 6: 171.

Page 2 of 4

\section{Methods}

A standard literature review was conducted of iodine status in women, particularly during pregnancy in view of the deleterious effects of deficiency on offspring. Articles were chosen by snowball sampling from reference lists of relevant articles and Australian government reports, and by searching key terms in PubMed. Key terms included: iodine, deficiency, female, pregnancy, fortification.

Inclusion criteria was studies performed on Australian cohorts and articles written in the English language. The outcomes assessed was iodine status, primarily the MUIC.

Non-literature primary sources of information were consulted for relevant datasets and include the Australian Bureau of Statistics (ABS) datasets from the relevant time periods, as well as published data from peer-review scholarly journals and government reports such as those of the Australian Institute of Health and Welfare (AIHW) [13].

\section{Discussion}

Tasmania implemented a voluntary food fortification program in 2001, eight years prior to the implementation of the nationwide program in 2009 [18]. As such, Tasmanian studies did not have the same pre- and post-fortification timeframes as other reports. Nevertheless, they were included in the analysis as they were still considered a valid measure of the efficacy of food fortification as a public health intervention.

Historically, New Zealand and some parts of Australia, notably Tasmania, had low iodine intakes partly due to low soil iodine levels [13]. Over the last decade, several studies had shown a re-emergence of iodine deficiency in parts of Australia and New Zealand and further studies in both countries confirmed that both populations were mildly deficient $[2,19]$. As the use of iodized salt has also declined since that time, intakes of iodine have fallen in both Australia and New Zealand, [20-25].

The 2003-04 Australian National Iodine Nutrition Study (ANINS), measured the iodine status of Australian school children aged 8-10 years in five Australian states [2]. Although this study pertains to children, studies such as those from Tasmania indicate that the MUIC in children provides a reliable estimate of the MUIC in adults $[18,26]$ The results of the ANINS showed that in NSW and Victoria, respectively, $58.5 \%$ and $72.6 \%$ of children were iodine deficient (urinary iodine excretion $<100 \mu \mathrm{g} / \mathrm{L}$ ) [2]. Children in Western Australia and Queensland were found to be iodine replete by comparison. The results from NSW and Victoria were very similar to those previously reported [27-29].

Studies specific to pregnant women demonstrated a high overall prevalence of iodine deficiency prior to food fortification. $72 \%$ of a sample of pregnant women in Western Sydney were iodine deficient, with 32\% suffering from moderate deficiency [30]. The MUIC of 81 $\mu \mathrm{g} / \mathrm{L}$ was similar to the level found in a pregnant population in Sydney approximately 10 years prior indicating that the situation had not improved despite publicity in the medical and lay press about iodine deficiency [27]. Similar reports of iodine deficiency from Victoria and Tasmania indicate the degree of iodine deficiency in pregnant women $(52 \mu \mathrm{g} / \mathrm{L})$ was even worse than in NSW $[11,18]$. There was a significant increase in MUIC in women who were taking a pregnancy supplement. At $115 \mu \mathrm{g} / \mathrm{L}$, however, it remained well below the recommended level of $150 \mu \mathrm{g} / \mathrm{L}$ [30].
Charlton et al. found a MUIC of $87.5 \mu \mathrm{g} / \mathrm{L}$ in a small sample of women attending an antenatal clinic in Wollongong. Their findings were similar in that the MUIC in the women taking a pregnancy supplement was significantly increased to $139 \mu \mathrm{g} / \mathrm{L}$, but still below the recommended level [31].

A study by Travers et al. found the MUIC for pregnant women was $85 \mu \mathrm{g} / \mathrm{L}$, indicating mild iodine deficiency. Almost $17 \%$ of pregnant women had a UIC $<50 \mu \mathrm{g} / \mathrm{L}$ [32]. Gunton et al. found a similar prevalence of moderate iodine deficiency among pregnant women in a Sydney teaching hospital (19.8\%) [20].

Hamrosi et al. investigated differences in iodine status in Vietnamese, Indian/Sri Lankan and Caucasian pregnant women residing in Melbourne. Like other studies in that region, iodine status was found to be much worse than in NSW. Non-Caucasian women had significantly better iodine status compared with Caucasian women, which the authors attributed to differences in dietary behaviours [11].

Mackerras et al. evaluated iodine status in Aboriginal Australians living in a remote area of the Northern Territory. The MUICs reported were below those reported in other parts of Australia. The authors admitted it could not be determined whether remoteness or ethnic factors were responsible for this discrepancy [33]. Given this is the only study prior to 2009 of iodine status in a defined Indigenous cohort, it could not be stated whether this group is at increased risk of iodine deficiency compared to non-Indigenous populations.

Data on iodine levels was collected in the 2011-12 National Health Measures Survey (NHMS) to provide national estimates and report on the effectiveness of mandatory iodine fortification [15]. The NHMS results showed that the Australian population median was a satisfactory $124.0 \mu \mathrm{g} / \mathrm{L}$ with $12.8 \%$ having a MUIC less than $50 \mu \mathrm{g} / \mathrm{L}$. There was variation across the country with adults in Western Australia having the highest median iodine levels $(157.4 \mu \mathrm{g} / \mathrm{L})$ and Tasmanians the lowest $(108.0 \mu \mathrm{g} / \mathrm{L})$. Comparison with the premandatory fortification ANINS suggests that MUIC has increased, although the baseline study contained data only for children [13].

Levels of iodine and rates of moderate iodine deficiency appear to have improved at a MUIC of $116 \mu \mathrm{g} / \mathrm{L} .18 .3 \%$ of all women had a MUIC $<50 \mu \mathrm{g} / \mathrm{L}$. Nearly two thirds $(62.2 \%)$ of women had an iodine level less than $150 \mu \mathrm{g} / \mathrm{L}$, which is the recommended level for all women who are pregnant, breastfeeding or considering pregnancy [17,34]. Pregnant women were not sampled in this study, however the results for women of childbearing years indicate that mandatory fortification may not be sufficient to meet the additional requirements in this group.

The National Aboriginal and Torres Strait Islander Health Measures Survey 2012-13 (NATSIHMS) was another nationwide survey, specifically targeting Aboriginal and Torres Strait Islanders [35]. The NATSIHMS showed that the Aboriginal and Torres Strait Islander adult population was iodine sufficient, with a population MUIC of $135.0 \mu \mathrm{g} / \mathrm{L}$. Only $10.8 \%$ had an iodine level of less than $50 \mu \mathrm{g} / \mathrm{L}$. Interestingly, Aboriginal and Torres Strait Islander adults had higher iodine levels than non-Indigenous adults (a median of $135.0 \mu \mathrm{g} / \mathrm{L}$ compared with $124.0 \mu \mathrm{g} / \mathrm{L}$ ) [34,36].

Although fortification has had favourable results in adults and children, several studies have demonstrated ongoing iodine deficiency in pregnant and breastfeeding women despite improvements in iodine status in the post-mandatory fortification period [37-39]. Indeed, the 
Citation: Wegrecki KJ, Sadig RR, Aramideh J, Khan N, Moawad D, Jabbour J, Yaourtis AM, et al. (2017) lodine Deficiency in Pregnant Women Pre- and Post-Mandatory lodine Fortification in Australia - An Epidemiological Review. Vitam Miner 6: 171.

Page 3 of 4

FSANZ predicted that most pregnant women would remain iodine deficient [12]. WHY?

At least one study has documented a failure to elicit any improvement in MUIC in pregnant women post-fortification [40]. The authors have suggested that pregnant women were unlikely to reach recommended iodine levels even after fortification without a dietary supplement.

Burgess et al. reported a non-significant increase in MUIC in pregnant women post-fortification in Tasmania, noting that iodine deficiency has persisted in this group despite being corrected in children [26].

A study in regional NSW found that only those women who were taking prenatal supplements containing iodine had MUICs indicating sufficiency $(150 \mu \mathrm{g} / \mathrm{L})$ post fortification [41]. The same result was found by a study looking at a sample of pregnant women in South Australia [42]. This is most likely explained by the increased iodine needs and renal iodide clearance induced by pregnancy, as previously stated.

Among pregnant women in 2011-2012, 60\%-66\% were taking supplements containing iodine [43]. This means that up to $40 \%$ of women were still not taking recommended iodine supplements, which the authors suggested might be due to women not being informed about the need for supplementation by their antenatal care providers, despite there being written advice on supplements provided in public health facilities across NSW. More recent studies have confirmed these poor rates of supplementation, as well as finding that only $18.5 \%$ of pregnant women believed they needed a supplement [44] and only $26 \%$ of family doctors reported discussing iodine supplementation with their pregnant patients [45]. For this reason, we strongly recommend further education of antenatal clinicians regarding the importance of iodine supplementation.

\section{Conclusions}

The literature review revealed that pregnant women were at significant risk of mild iodine deficiency pre-fortification. Those who took an iodine supplement had significantly better iodine status, but remained below the recommended level for pregnant women. Caucasian women appeared to be at greatest risk of iodine deficiency.

The results also indicated that MUICs had not changed substantially for pregnant women over the decade preceding mandatory fortification in 2009 despite attempts to improve iodine nutrition in the population.

Despite iodine status improving in children and adults, pregnant women appear to have had insufficient improvement in iodine levels post mandatory iodine fortification. Dietary supplementation with iodine was needed to prevent iodine deficiency during pregnancy.

Continuing national public health education and supplementation programs are necessary to ensure that adequate iodine requirements are met for all pregnant women.

\section{Recommendations}

Ongoing surveillance of the iodine status of Australian communities to establish trends over time is recommended. Given the small sample sizes of most of the studies included in this report and paucity of data in pregnant women, there is a need for more robust research on the impact of fortification of foods and supplementation on iodine status of pregnant women in particular.

Of note, there were no studies of MUIC of pregnant or breastfeeding women in Western Australia or Queensland that were conducted to determine if there are differences across states.

In light of the results presented in the current report, public health strategies, including nutritional education and supplementation, are urgently required to improve the iodine status of pregnant women.

Additionally, education of antenatal clinicians regarding the importance of iodine supplementation is strongly recommended.

\section{References}

1. Eastman CJ (1999) Where has all our iodine gone? The possible reemergence of iodine deficiency in Australia needs to be investigated in national surveys. Med J Aust 171: 455-456.

2. Li M, Eastman CJ, Waite KV, Ma G, Byth K, et al. (2006) Are Australian children iodine deficient? Results of the Australian National 184: 165-169.

3. Li M, Chapman S, Agho K, Eastman CJ (2008) Can even minimal news coverage influence consumer health-related behaviour? A case study of iodized salt sales, Australia. Health Educ Res.

4. Eastman CJ (2005) Iodine supplementation: the benefits for pregnant and lactating women in Australia and New Zealand. 7: 65-66.

5. Burrow G (2008) World Health Organization. Assessment of Iodine Deficiency Disorders and Monitoring Their Elimination. A Guide for Programme Managers, Geneva, pp: 1-108.

6. Glinoer D (2007) The importance of iodine nutrition during pregnancy. Public Health Nutr 10: 1542-1546.

7. Qian M, Wang D, Watkins WE, Gebski V, Yan YQ, et al. (2005) The effects of iodine on intelligence in children: a meta-analysis of studies conducted in China. Asia Pac J Clin Nutr 14: 32-42.

8. Zimmermann MB, Jooste PL, Pandav CS (2008) Iodine-deficiency disorders. Lancet. 372: 1251-1262.

9. Hynes KL, Otahal P, Hay I, Burgess JR (2013) Mild iodine deficiency during pregnancy is associated with reduced educational outcomes in the offspring: 9-year follow-up of the gestational iodine cohort. J Clin Endocrinol Metab 98: 1954-1962.

10. Bath SC, Steer CD, Golding J, Emmett P, Rayman MP (2013) Effect of inadequate iodine status in UK pregnant women on cognitive outcomes in their children: Results from the Avon Longitudinal Study of Parents and Children (ALSPAC). Lancet 382: 331-337.

11. Hamrosi MA, Wallace EM, Riley MD (2005) Iodine status in pregnant women living in Melbourne differs by ethnic group. Asia Pac J Clin Nutr 14: 27-31.

12. FSANZ (2008) Approval Report: Proposal P1003-mandatory Iodine Fortification for Australia. Canberra, pp: 1-105.

13. Australian Institute of Health and Welfare (2016) Monitoring the health impacts of mandatory folic acid and iodine fortification. Cat. no. PHE 208.

14. Zimmermann MB (2009) Iodine deficiency. Endocr Rev 30: 376-408.

15. Australian Bureau of Statistics (2013) Australian Health Survey: User's Guide, 2011-13. ABS cat

16. World Health Organization Assessment of the iodine deficiency disorders and monitoring their elimination. WHO, Geneva, pp: 1-107.

17. National Health and Medical Research Council (2010) NHMRC Public Statement: Iodine supplementation for pregnant and breastfeeding women.

18. Seal JA, Doyle Z, Burgess JR, Taylor R, Cameron AR (2007) Iodine status of Tasmanians following voluntary fortification of bread with iodine. Med J Aust 186: 69-71. 
Citation: Wegrecki KJ, Sadig RR, Aramideh J, Khan N, Moawad D, Jabbour J, Yaourtis AM, et al. (2017) lodine Deficiency in Pregnant Women Pre- and Post-Mandatory lodine Fortification in Australia - An Epidemiological Review. Vitam Miner 6: 171.

Page 4 of 4

19. Parnell W, Scragg R, Wilson N, Schaaf D, Fitzgerald E (2003) NZ Food NZ Children: Key Results of the 2002 National Children's Nutrition Survey. Wellington, pp: 1-289.

20. Gunton JE, Hams G, Fiegert M, McElduff A (1999) Iodine deficiency in ambulatory patients at a Sydney teaching hospital: is Australia truly iodine replete? Med J Aust 171: 467-470.

21. Hynes KL, Blizzard CL, Venn AJ, Dwyer T, Burgess J (2004) Persistent iodine deficiency in a cohort of Tasmanian school children: associations with socio-economic status, geographic location and dietary factors. Aust Public Health 28: 476-481.

22. Skeaff SA, Thomson CD, Gibson RS (2002) Mild iodine deficiency in a sample of New Zealand schoolchildren. Eur J Clin Nutr 56: 1169-1175.

23. Skeaff S, Ferguson E, Valeix P, Gibson R, Thomson CD (2005) Are breastfed infants and toddlers in New Zealand at risk of iodine deficiency? Nutrition 21: 325-331.

24. Thomson CD, Packer MA, Butler JA, Duffield AJ, O’Donaghue Kl, et al. (2001) Urinary selenium and iodine during pregnancy and lactation. J Trace Elem Med Biol 14: 210-217.

25. Thomson CD (2004) Selenium and iodine intakes and status in New Zealand and Australia. Br J Nutr 91: 661-672.

26. Burgess JR, Seal JA, Stilwell GM, Reynolds PJ, Taylor ER, et al. (2007) A case for universal salt iodisation to correct iodine deficiency in pregnancy: another salutary lesson from Tasmania. Med J Aust 186: 574-576.

27. Li M, Ma G, Guttikonda K, Boyages SC, Eastman CJ (2001) Reemergence of iodine deficiency in Australia. Asia Pac J Clin Nutr 10: 200-203.

28. McDonnell CM, Harris M, Zacharin MR (2001) Iodine deficiency and goitre in schoolchildren in Melbourne. Med J Aust 178: 159-162.

29. McElduff A, McElduff P, Gunton JE, Hams G, Wiley V, et al. (2002) Neonatal thyroid-stimulating hormone concentrations in northern Sydney: further indications of mild iodine deficiency? Med J Aust 176: 317-320.

30. Blumenthal N, Byth K, Eastman CJ (2012) Iodine intake and thyroid function in pregnant women in a private clinical practice in northwestern sydney before mandatory fortification of bread with iodised salt. J Thyroid Res 2012: 6.

31. Charlton KE, Gemming L, Yeatman H, Ma G (2010) Suboptimal iodine status of Australian pregnant women reflects poor knowledge and practices related to iodine nutrition. Nutrition 26: 963-968.

32. Travers CA, Guttikonda K, Norton CA, Lewis PR, Mollart LJ, et al. (2006) Iodine status in pregnant women and their newborns: Are our babies at risk of iodine deficiency? Med J Aust 184: 617-620.

33. Mackerras DEM, Singh GR, Eastman CJ (2011) Iodine status of Aboriginal teenagers in the Darwin region before mandatory iodine fortification of bread. Med J Aust 194: 126-130.
34. Australian Bureau of Statistics (2013) Australian Health Survey: Biomedical Results for Nutrients, 2011-12. ABS cat. no. 4364.0.55.006.

35. Australian Bureau of Statistics. (2014) Australian Aboriginal and Torres Strait Islander Health Survey: Users' Guide, 2012-13. ABS cat. no. 4727.0.55.002.

36. Australian Bureau of Statistics (2012) Australian Aboriginal and Torres Strait Islander Health Survey: Biomedical Results, 2012-13. ABS cat. no. 4727.0.55.003. 2014.

37. Clifton VL, Hodyl NA, Fogarty PA, TorpyJ, Roberts R, et al. (2013) The impact of iodine supplementation and bread fortification on urinary iodine concentrations in a mildly iodine deficient population of pregnant women in South Australia. Nutr J 12: 32.

38. Huynh D, Condo D, Gibson R, Makrides M, Muhlhausler B, et al. (2017) Comparison of breast-milk iodine concentration of lactating women in Australia pre-and post-mandatory iodine fortification. Public Health Nutr 20: 12-17.

39. Axford S, Charlton K, Yeatman H, Ma G (2011) Improved iodine status in breastfeeding women following mandatory fortification. Aust NZ J Public Health 35: 579-580.

40. Rahman A, Savige GS, Deacon NJ, Chesters JE, Panther BC (2011) Urinary iodine deficiency in Gippsland pregnant women: The failure of bread fortification? Med J Aust 194: 240-243.

41. Charlton KE, Yeatman H, Brock E, Lucas C, Gemming L, et al. (2013) Improvement in iodine status of pregnant Australian women 3 years after introduction of a mandatory iodine fortification programme. Prev Med 57: 26-30

42. Condo D, Huyhn D, Anderson AJ, Skeaff S, Ryan P, et al. (2016) Iodine status of pregnant women in South Australia after mandatory iodine fortification of bread and the recommendation for iodine supplementation. Matern Child Nutr.

43. Charlton K, Yeatman H, Lucas C, Axford S, Gemming L, et al. (2012) Poor knowledge and practices related to iodine nutrition during pregnancy and lactation in australian women: Pre- and post-iodine fortification. Nutrients 4: 1317-1327.

44. Martin JC, Savige GS, Mitchell EKL (2014) Health knowledge and iodine intake in pregnancy Aust New Zeal J Obstet Gynaecol 54: 312-316.

45. Lucas CJ, Charlton KE, Brown L, Brock E, Cummins L (2014) Antenatal shared care: Are pregnant women being adequately informed about iodine and nutritional supplementation? Aust New Zeal J Obstet Gynaecol 54: 515-521. 